\title{
Resumption of Puberty in Girls and Boys with Central Precocious Puberty After Withdrawal of Long-Term Therapy with LHRH-Analogue D-Ser-6-LHRH
}

\author{
Hatae Maesaka, Seizo Suwa, Katsuhiko Tachibana, Yumi Asakura and Masanori Adachi \\ Department of pediatrics, Kanagawa Children's Medical Center, Yokohama, Japan
}

\begin{abstract}
There are few reports about reactivation of gonadal function and progress through puberty after withdrawal of therapy with LHRH-A in patients with central precocious puberty (CPP). Eight patients (5 females and 3 males) with CPP were treated with LHRH-A (D-Ser ${ }^{6}$ LHRH) with a dose of $10 \mu \mathrm{g} / \mathrm{kg}$ by single or twice daily subcutaneous injections for periods ranging from 3 to 5.3 years. We have studied 30-day consecutive patterns of first morning voided urinary gonadotropin and ovarian hormone excretion in these patients during and after withdrawal of therapy with LHRH-A. During the treatment, the mean and maximum concentrations of urinary LH and FSH in 7 patients studied were low. After withdrawal of therapy, a rapid resumption of puberty was observed in 3 patients, who also had a hypothalamic hamartoma. In the remaining 5 patients with idiopathic CPP, the testes increased rapidly in size in one boy; but among 4 girls, only 1 had regular menstruation and the other 3 had irregular or no menstruation. The urinary patterns of these hormones did not return quickly to a pubertal pattern after withdrawal of treatment in these girls. This may be partly related to the long-term use of LHRH-A, but seems to be partly caused by psychological factors. These patients treated with long-term LHRH-A will head follow-up and evaluation of the reproductive function.
\end{abstract}

Key words: central precocious puberty, LHRH-analogue, resumption of puberty, urinary gonadotropins, LHRH test

Until recently, there was no effective and safe treatment for central precocious puberty (CPP). The progestational agents, medroxy-

Received: September 6, 1993

Accepted: April 27, 1994

Correspondence: Dr. Hatae Maesaka, Department of Pediatrics, Kanagawa Children's Medical Center, Mutsukawa, 2-138-4, Minami-ku, Yokohama 232 Japan

Supported by a research grant for specific disease from the Japanese Ministry of Health and Welfare and by a comprehensive research grant for prevention of mental and physical disorders awarded by the Japanese Ministry of Health and Welfare. progesterone acetate and cyproterone acetate, have been used. However, their effects in reducing bone maturation have not been remarkable, and there have been some sideeffects $^{12) 3)}$.

Recently, LHRH analogues have been used for treatment of CPP in boys and girls. These agents at first stimulate and thereafter suppress pituitary gonadotropin secretion, and decrease the levels of circulating sex steroids. By using this therapy for patients with 
CPP, suppression of pubertal development and reduced bone maturation have been reported in many pediatric centers ${ }^{4) 5(6) 7}$. Even after prolonged treatment, suppressed gonadotropin secretion is thought to be reversible and puberty is expected to develop normally after withdrawal of therapy. However, there are few reports about the reactivation of gonadal function and the development of puberty after withdrawal ${ }^{8) 9(10) 11)}$.

We have developed and already reported $^{12)}$ a simple and improved method for the quantification of urinary gonadotropins, which requires amounts of urine smaller than those previously reported. First morning voided (FMV) urine specimens have been used as a satisfactory alternative to serial ovarian hormone measurements ${ }^{13}$. We have also reported $^{14)}$ the patterns of urinary gonadotropins, total estrogen and pregnanediol in serial FMV urine specimens obtained over a 1-month period from normal prepubertal and pubertal children. Using this method, we have studied the patterns of consecutive FMV urinary gonadotropin and sex steroid excretion in patients with CPP during and after withdrawal of therapy with an LHRH analogue, D-Ser'-LHRH (Buserelin). We would like to present the process of resumption of gonadal function after withdrawal of LHRH-A in these patients.

\section{Subjects}

According to clinical criteria, the diagnosis of CPP was established when breast budding appeared before the age of 7 , pubic hair with breast budding before the age of 8 , or menarche before the age of 9 in girls, and when testes and penis progressed to Tanner stage 2 before the age of 9 and the same changes associated with pubic hair appeared before the age of 10 in boys. The clinical data of 5 girls and 3 boys included in this study are presented in Tables and 2. Three patients (1 female and 2 males) had a hypothalamic hamartoma and 5 had idiopathic CPP. Before the therapy, 2 females (patients 1 and 5 ) had genital bleeding at the ages of 3 months and 5 yrs 11 months. The patients were treated with LHRH-A, D-Ser ${ }^{6}-$ LHRH, kindly supplied by Hoechst Japan, for periods ranging from 3 to 5.3years. It was administered at a dose of $10 \mu \mathrm{g} / \mathrm{kg}$ by twice daily subcutaneous injection to 6 patients and by a single daily injection together with application of an intranasal spray of LHRH-A (Buseelin) three times a day to patients 1 and 7 by their parents. Bone maturation was evaluated according to the criteria of Greulich and Pyle. In these patients, the decision to withdraw the therapy was made when bone age exceeded. 13.5 years, predicted final height was satisfactory, and chronological age was appropriate for the development of puberty.

\section{Materials and Methods}

Routine measurements of $\mathrm{LH}$ and FSH in serum without extraction and urine after ammonium sulfate extraction were made by a polyclonal double antibody RIA kit obtained from Eiken Co,. Tokyo, Japan. Extraction and RIA procedures were the same as in our previous study ${ }^{12)}$. Urinary total estrogen (conjugated and unconjugated) and pregnanediol were measured by means of the previously reported method $^{15) 16)}$. Creatinine concentration in the urine was measured by the Jaffe reaction using an autoanalizer. All specimens from a single subject were assayed by the same RIA. Values were expressed as mean and SEM.

\section{Results}

(1) Clinical and endocrinological effects (Table 1,2)

During the treatment, 3 girls had a decrease and 2 girls had no further increase in breast size. In boys, one had a decrease and 2 had no further increase in testicular size. Suppression of bone maturation occured with conlinued therapy in all patients. 
Table 1. Clinical and endocrinological data in 5 female patients with central precocious puberty (CPP) at start and end of treatment with LHRH-A (D-Ser ${ }^{6}$-LHRH)

Pubertal stage according to Tanner. B: breast, Phair: pubic hair, M: menarche, CA: chronological age, BA: bone age, CyA: cyproterone acetate

\begin{tabular}{|c|c|c|c|c|c|c|c|c|c|c|c|c|c|c|}
\hline \multirow[t]{3}{*}{ etiology } & \multirow{2}{*}{\multicolumn{3}{|c|}{$\begin{array}{c}\text { Age at } \\
\text { pubertal sign }\end{array}$}} & \multirow{3}{*}{$\begin{array}{c}\text { pre- } \\
\text { treatment }\end{array}$} & \multirow{2}{*}{\multicolumn{4}{|c|}{$\begin{array}{l}\text { At start of treat- } \\
\text { ment with LHRH-A } \\
\text { Tanner }\end{array}$}} & \multirow{2}{*}{\multicolumn{5}{|c|}{$\begin{array}{c}\text { At end of treat- } \\
\text { ment with LHRH-A }\end{array}$}} & \multirow{2}{*}{$\begin{array}{l}\text { Duration } \\
\text { of }\end{array}$} \\
\hline & & & & & & & & & & & & & & \\
\hline & $\mathrm{B}$ & Phair & $\mathrm{M}$ & & $\mathrm{CA}$ & $\mathrm{BA}$ & & stage & & $\mathrm{CA}$ & $\mathrm{BA}$ & & stage & treatment \\
\hline & $\mathrm{yr}$ & $\mathrm{yr}$ & $\mathrm{yr}$ & & $\mathrm{yr}$ & $\mathrm{yr}$ & B & Phart & M & $\mathrm{yr}$ & yr & B & Phair & yr \\
\hline 1F IM idiopathic & 4.6 & - & - & СуA & 6.3 & 9.6 & 3 & 2 & + & 12.0 & 12.9 & 2 & 2 & 5.3 \\
\hline 2F TK idiopathic & 4.3 & - & - & - & 7.1 & 11.0 & 3 & 1 & - & 12.4 & 12.3 & 3 & 2 & 5.2 \\
\hline 3F KT idiopathic & 6.3 & 7.7 & - & - & 8.0 & 11.0 & 3 & 2 & - & 12.4 & 13.5 & 3 & 3 & 4.4 \\
\hline 4F OA idiopathic & 6.8 & 8.6 & - & - & 8.6 & 11.0 & 3 & 2 & - & 12.0 & 13.0 & 1 & 2 & 3.4 \\
\hline 5F IM hamartoma & 2.0 & - & 0.3 & СуA & 8.1 & 10.5 & 3 & 2 & + & 11.3 & 11.5 & 2 & 1 & $\underline{3.3}$ \\
\hline & & & & mean & 7.6 & 10.6 & & & mean & 12.0 & 12.6 & & mean & $\overline{4.3}$ \\
\hline & & & & $\pm \mathrm{SD}$ & \pm 0.9 & \pm 0.6 & & & $\pm \mathrm{SD}$ & \pm 0.4 & \pm 0.8 & & $\pm \mathrm{SD}$ & \pm 1.0 \\
\hline
\end{tabular}

Table 2. Clinical and endocrinological data in 3 male patients with CPP at start and end of treatment with LHRH-A Pubertal stage according to Tanner. B: breast, Phair: pubic hair, G: genitalia, CA: chronological age, BA: bone age, CyA: cyproterone acetate

\begin{tabular}{|c|c|c|c|c|c|c|c|c|c|c|c|c|}
\hline \multirow[t]{3}{*}{ case } & \multicolumn{2}{|c|}{$\begin{array}{l}\quad \text { Age at } \\
\text { pubertal sign } \\
\text { increased Phair } \\
\text { testicular }\end{array}$} & \multirow[t]{2}{*}{$\begin{array}{c}\text { pre- } \\
\text { treatment }\end{array}$} & \multicolumn{4}{|c|}{$\begin{array}{l}\text { At start of treat- } \\
\text { ment with LHRH-A } \\
\begin{array}{c}\text { Tanner } \\
\text { stage }\end{array}\end{array}$} & \multicolumn{4}{|c|}{$\begin{array}{l}\text { At end of treat- } \\
\text { ment with LHRH-A } \\
\begin{array}{c}\text { Tanner } \\
\text { stage }\end{array}\end{array}$} & \multirow[t]{2}{*}{$\begin{array}{l}\text { Duration } \\
\text { of } \\
\text { treatment }\end{array}$} \\
\hline & volume & & & $\mathrm{CA}$ & $\mathrm{BA}$ & & & $\mathrm{CA}$ & $\mathrm{BA}$ & & & \\
\hline & $\mathrm{yr}$ & $\begin{array}{c}\mathrm{yr} \\
3 \mathrm{1}\end{array}$ & & $\begin{array}{l}\mathrm{yr} \\
6.2\end{array}$ & $\begin{array}{c}\mathrm{yr} \\
10.5\end{array}$ & $\begin{array}{l}\mathrm{G} \\
3\end{array}$ & $\begin{array}{c}\text { Phair } \\
2\end{array}$ & $\begin{array}{c}\mathrm{yr} \\
11.6\end{array}$ & $\begin{array}{c}\mathrm{yr} \\
14.0\end{array}$ & $\begin{array}{l}\mathrm{G} \\
2\end{array}$ & $\begin{array}{l}\text { Phair } \\
2\end{array}$ & $\begin{array}{l}\mathrm{yr} \\
5.3\end{array}$ \\
\hline & 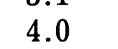 & 4.0 & CyA & 5.3 & 13 & 3 & 3 & 9.4 & 14.0 & 3 & 3 & 4.0 \\
\hline бата & 9.0 & 9.0 & - & 10.2 & 10.4 & 3 & 3 & $\frac{15.2}{10.1}$ & $\frac{14.0}{110}$ & 3 & 3 & $\frac{4.9}{4.7}$ \\
\hline & & & $\begin{array}{l}\text { mean } \\
\pm \mathrm{SD}\end{array}$ & $\begin{array}{r}7.2 \\
\pm 2.6\end{array}$ & $\begin{array}{r}11.3 \\
\pm 1.5\end{array}$ & & $\begin{array}{l}\text { mean } \\
\pm \mathrm{SD}\end{array}$ & $\begin{array}{r}12.1 \\
\pm 2.9\end{array}$ & 14.0 & & $\begin{array}{l}\text { mean } \\
\pm \mathrm{SD}\end{array}$ & $\begin{array}{r}4.7 \\
\pm 0.7\end{array}$ \\
\hline
\end{tabular}

All patients had pubertal basal serum LH and FSH levels and a pubertal response to LHRH before treatment except one (patient 2) (Fig. 1). Patient 2 had only an early pubertal response to LHRH before treatment. Within 6 months after the onset of treatment with LHRH-A, the levels of serum basal and peak post-LHRH gonadotropins were suppressed significantly in all patients (data not shown). At the end of treatment, the levels of basal serum gonadotropins had remained low in all patients, with a low response to LHRH in 5 patients studied.
One month after treatment with LHRH-A, serum sex steroid concentrations had fallen rapidly to prepubertal ranges in all patients (data not shown). At the end of treatment, basal sex steroid values were low in all patients (Figs 1 and 2). Six-9 months after withdrawal, serum values of basal and peak post-LHRH gonadotropins and testosterone rapidly returned to pubertal levels in all boys. From 12 to 14 months after withdrawal, these hormone levels increased further in all boys (Fig. 2). However, from 3 to 6 months after withdrawal of LHRH-A therapy from the 


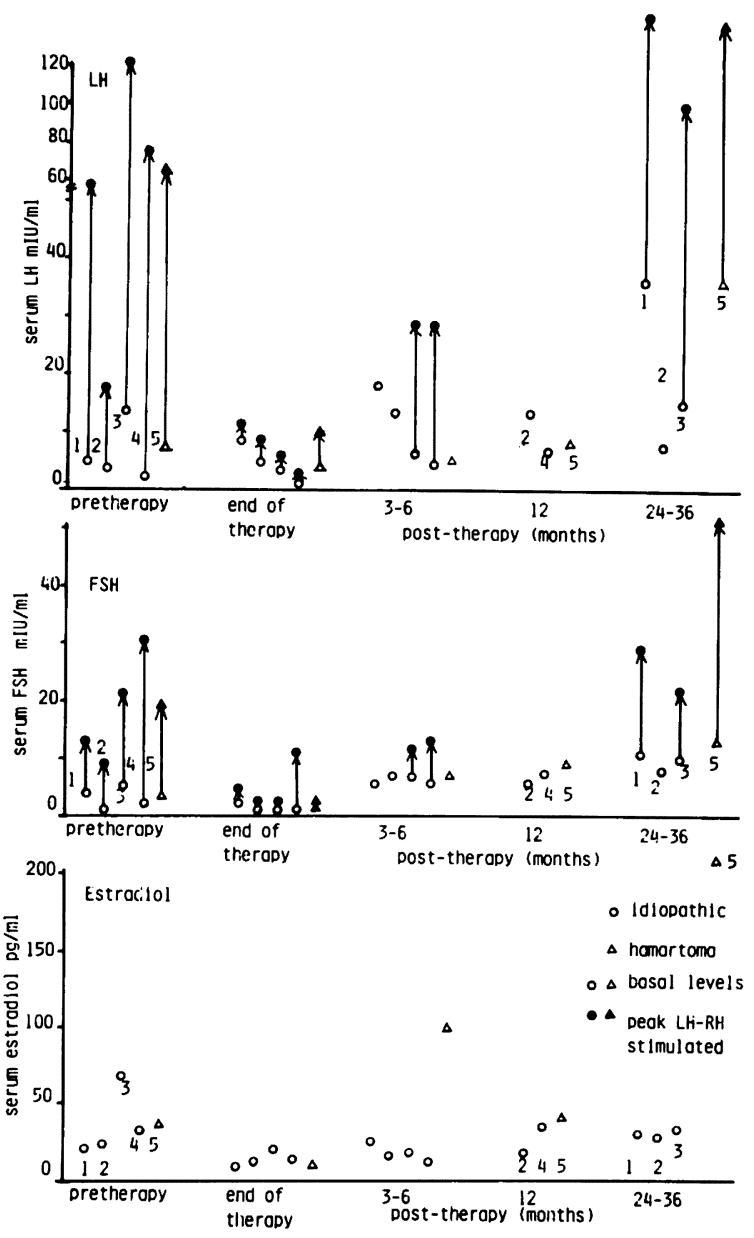

Fig. 1. Basal levels of serum estradiol, basal and peak post-LHRH plasma LH and FSH levels in girls with CPP before, during and after LHRH-A therapy girls, the basal levels of serum gonadotropins and estradiol were different in each patient. In one girl (patient 5) who had a hypothalamic hamartoma, serum estradiol returned to pubertal levels and menstruation occurred within 3 months after withdrawal. In the other 2 patients ( $3 \& 4)$, peak post-LHRH LH and FSH increased, but did not attain the pubertal ranges from 3 to 6 months after withdrawal. From 24 to 36 months after withdrawal, serum basal and peak post-LHRH LH and $\mathrm{FSH}$ returned to pubertal ranges in three girls (patients 1,3,5).

(2) The patterns of monthly urinary gonadotropin and sex steroid excretion

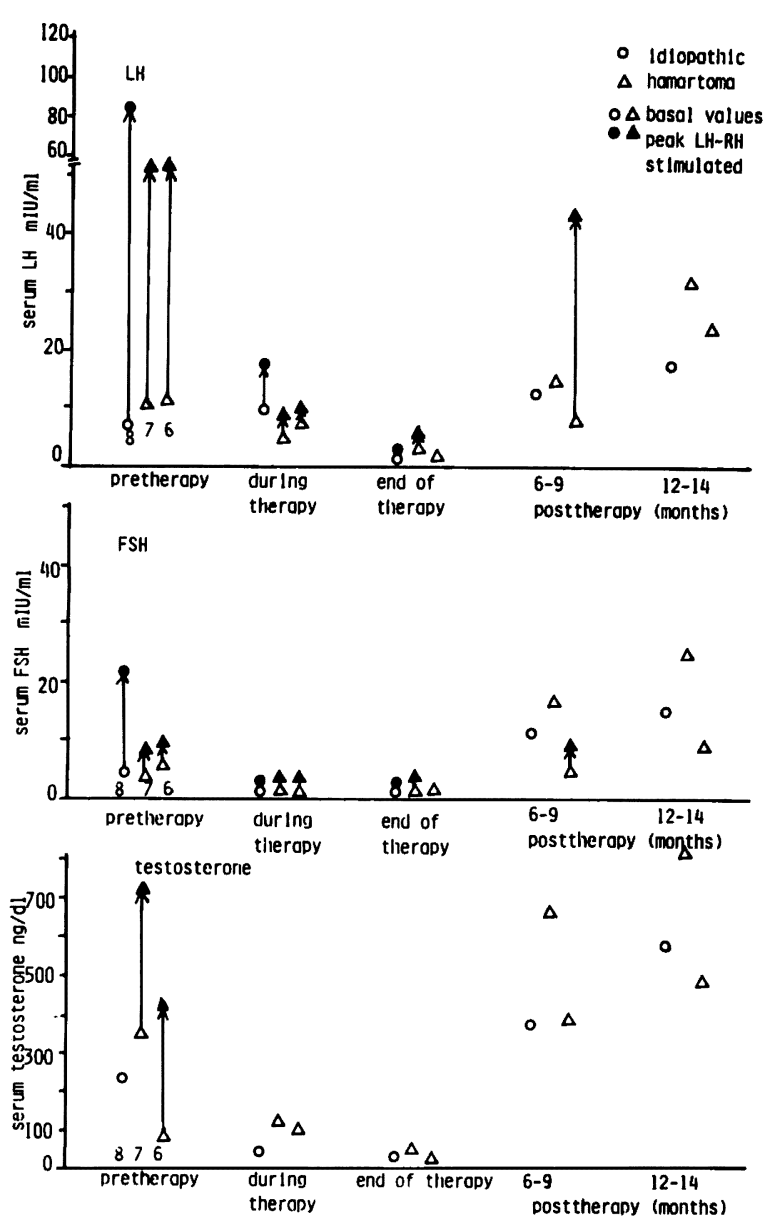

Fig. 2. Basal levels of serum testosterone, basal and peak post-LHRH plasma LH and FSH levels in boys with CPP before, during and after LHRH-A therapy

during and after withdrawal of LHRH-A therapy

During the treatment, the mean and maximum concentrations of monthly urinary LH in 7 patients studied were significantly low compared with those of sexually stagematched normal children as previously reported $^{14)}$ (Table 3). Among the female patients treated for more than 3.3 years, the mean values of urinary $\mathrm{FSH}$ in patient 1 treated with a single daily subcutaneous injection of LHRH-A and patient 5, who had a hamartoma, were higher than those of the other 2 female patients treated with twice daily injections of LHRH-A (Table 3). These urinary 
Table 3. Monthly urinary gonadotropin and sex steroid excretion in patients with CPP during and after withdrawal of LHRH-A therapy

CA: chronological age, Max: maximum value. Pdiol: pregnanediol

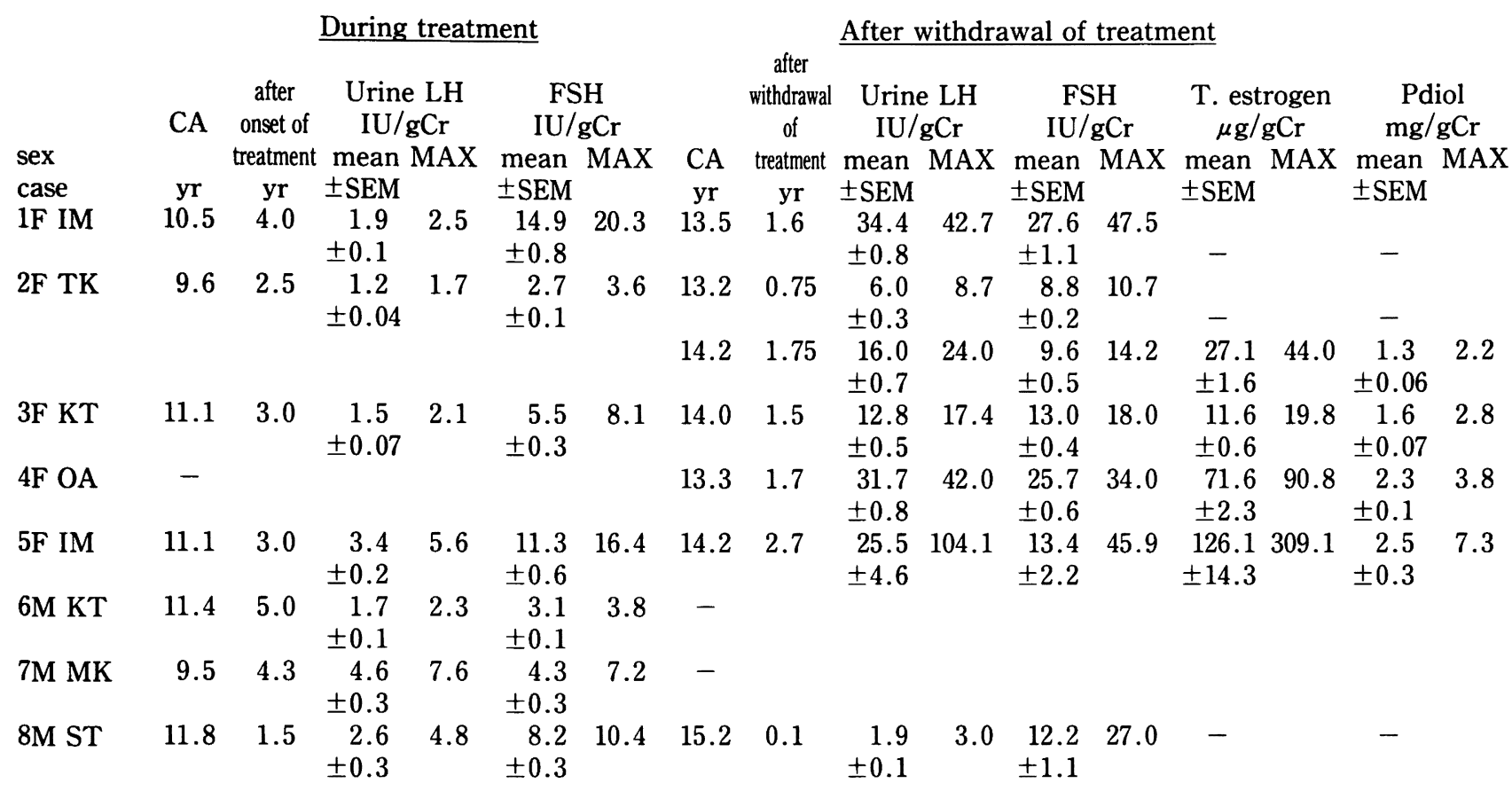

patterns in patients 1 and 5 were similar to those of normal prepubertal children (Figs 3 and 4). The urinary patterns during treatment of patients 2 and 3 were rather similar to those of hypogonadotropic hypogonadism. The mean concentration of monthly urinary $\mathrm{LH}$ excretion 1.6 years after withdrawal of treatment increased significantly, and that of FSH slightly, compared with the values during treatment in patient 1 . Among the premenstrual patterns in urine taken after treatment, urinary $\mathrm{LH}$ and $\mathrm{FSH}$ values in patient 1 were higher than those in the other females (patients 2 and 3)(Fig. 3 and Table 3). The patterns of patients 1 and 4 were similar to those of normal mid-pubertal girls (Figs 3 and 5). The mean excretions of urinary LH, FSH, total estrogen and pregnanediol 1.5 years posttreatment were low, with a few fluctuations in patient 3 . These monthly urinary patterns in patients 2 and 3 were not similar to those of normal prepubertal and early pubertal girls and were thought to be abnormal (Figs 3 and
5). From 20-24 months after withdrawal of LHRH-A, patients 1 and 3 showed pubertal serum LH and FSH responses to LHRH (Fig. 1). From the next month, patient 1 had regular menstruation, but patient 3 had no menstruation. Three months post-treatment, remenstruation occurred and continued regularly in patient 5 . Three years post-treatment, patient 5 showed monthly urinary patterns similar to those seen in normal-cycled female adolescents, as previously reported ${ }^{14)}$ (Fig. 4). The values of prevulatorily excreted urinary total estrogen and pre-menstrually excreted urinary pregnanediol in patient 5 were relatively low compared with those of a normal female adult.

(3) Resumption of puberty after withdrawal of treatment with LHRH-A

From 5 to 9 months after withdrawal of therapy in all male patients, testicular volumes increased from 5-6ml to 8-9ml and pubic hair developed progressively. Twenty-four months after withdrawal of therapy in all 
MAESAKA et al.
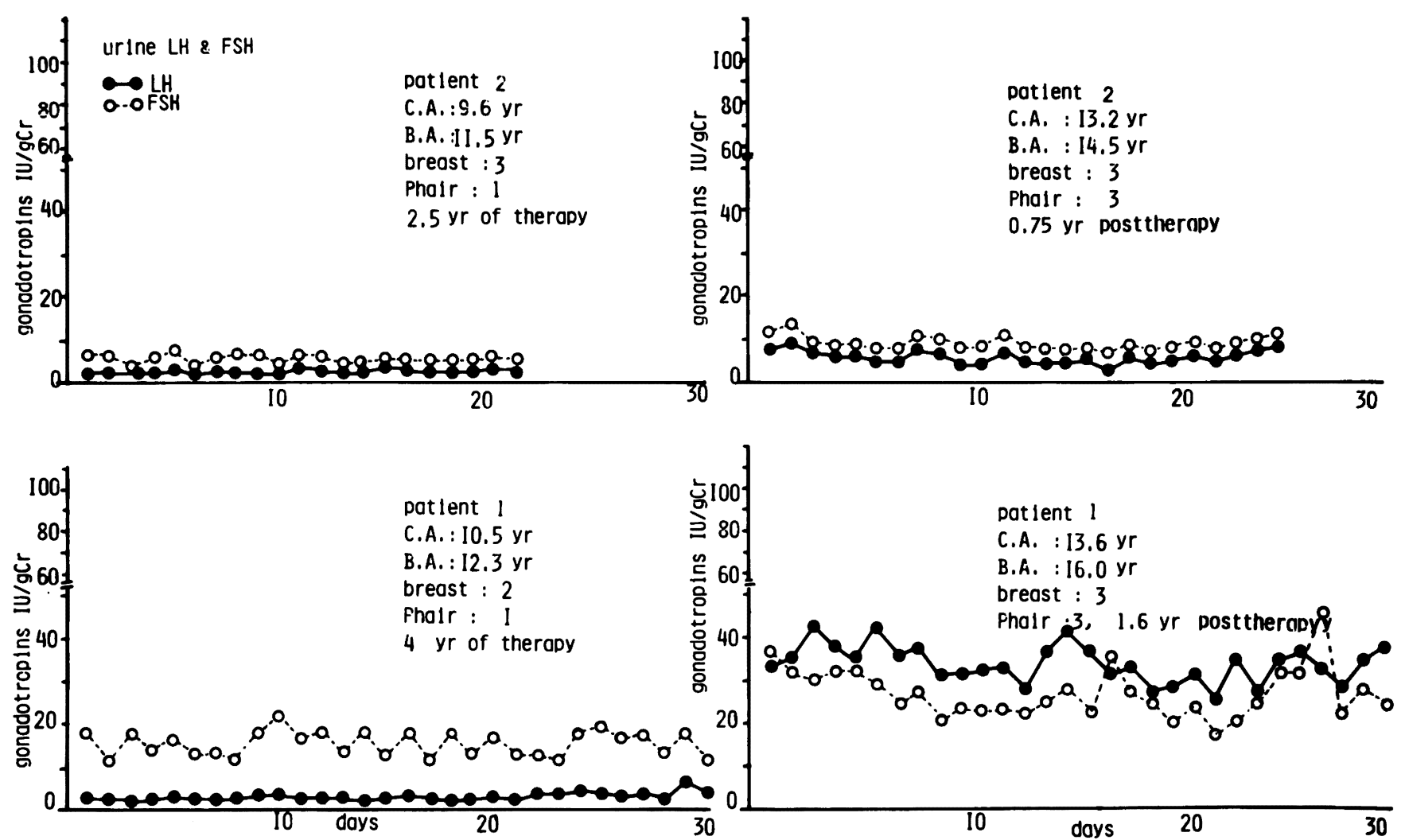

Fig. 3. Urinary gonadotropin excretory patterns in two patients $(1 \& 2)$ with CPP during and after therapy with LHRH-A

CA: chronological age, Phair: pubic hair, BA: bone age
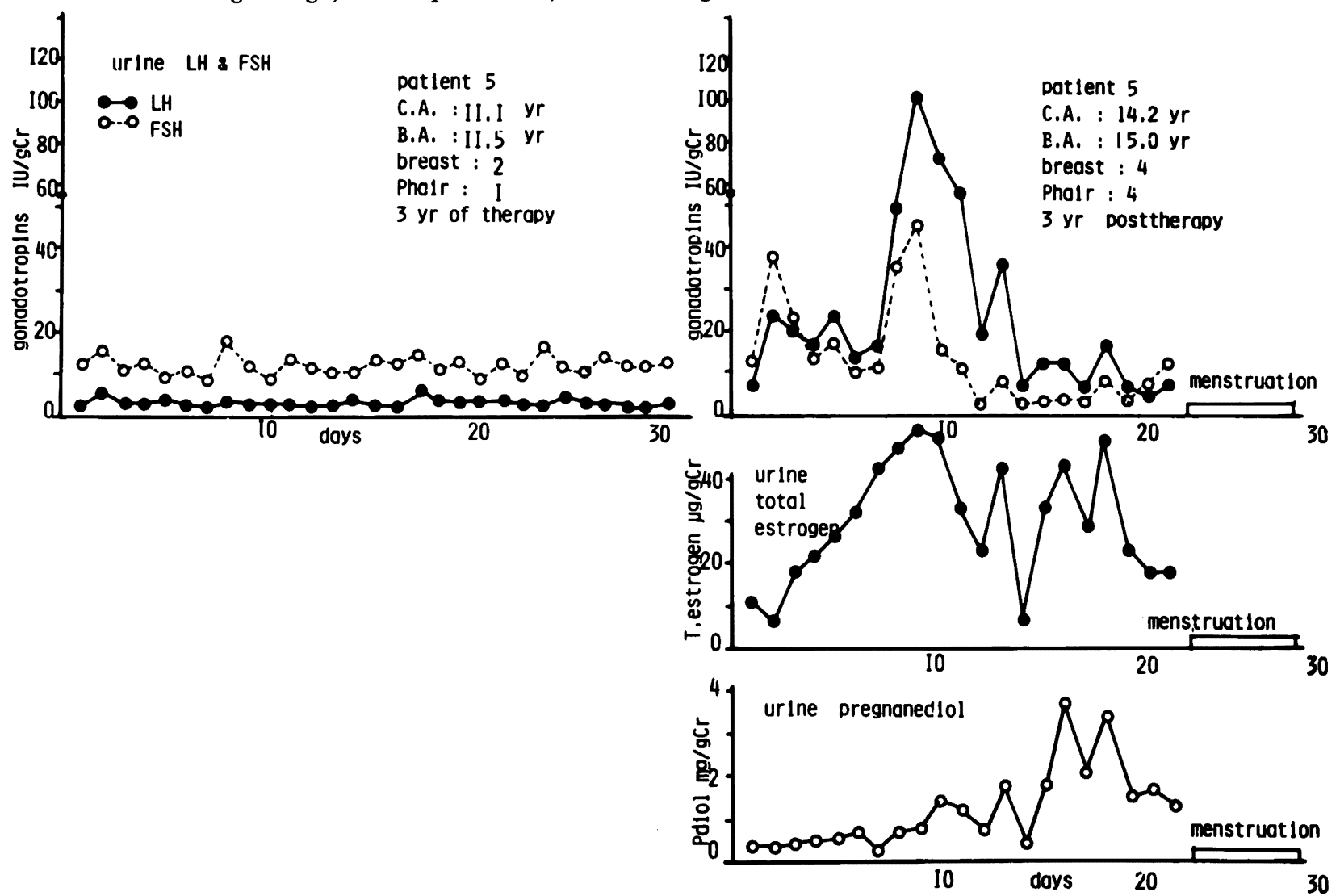

Fig. 4. Urinary gonadotropin and ovarian hormone excretory patterns in a patient 5 with CPP due to a hamartoma during and after therapy with LHRH-A 

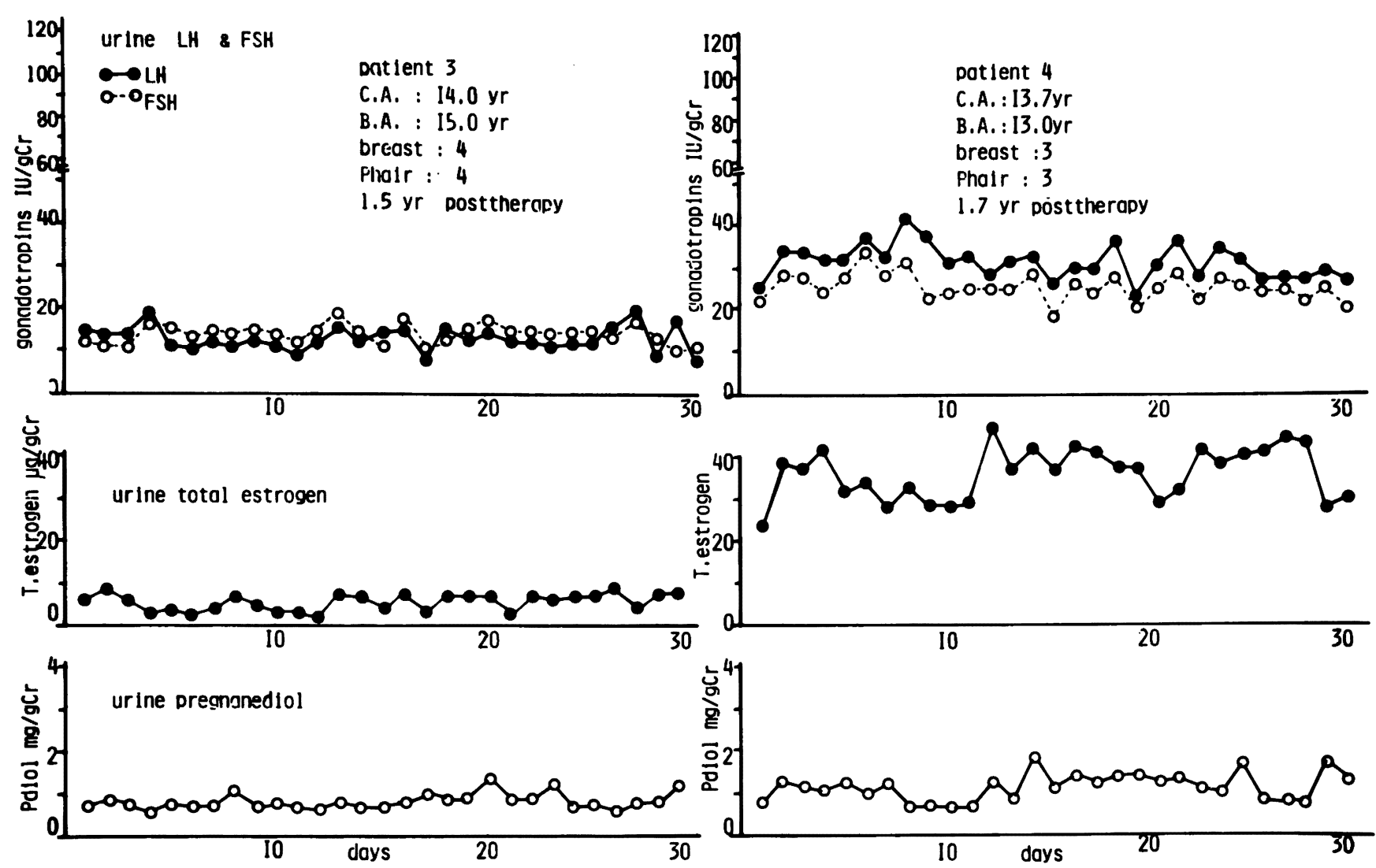

Fig. 5. Urinary gonadotropin and ovarian hormone excretory patterns in two patients ( 3 \& 4) with CPP after therapy with LHRH-A

male patients, testicular volume and pubic hair increased and attained the adult range.

In all girls, breast and pubic hair also developed progressively. Within 12 months after withdrawal of LHRH-A, menses occurred in patient 5 ; thereafter, she had regular menstruation until now. During a follow-up period of 12-24 months, menses occurred in 3 (patients 1,2,4) among the 4 girls. Patient 1 had regular menses following an LHRH loading test, and the other 2 patients had a spontaneous menarche. Patient 2 had irregular menses and patient 4 had some after menarche. Patient 2 suffered from psychological stress until entry to high school. Patient 4 had disturbed menstrual cycles for no known reason in middle school. Patient 3 had hard exercise almost every day in the sports division of middle school, and had not reached menarche at the last vist, 2.3 years after discontinuation of LHRH-A. The sonographic findings in patient 4 after withdrawal of treatment with LHRH-A were normal.

\section{Discussion}

The reversibility of the pituitary suppression after withdrawal of short-term treatment with LHRH-A has been well established ${ }^{8) 17}$. However, there are few data available concerning reactivation of gonadal function in patients with CPP after withdrawal of longterm treatment with LHRH-A. Manasco PK et $a l{ }^{8)}$ reported that menstruation occurred and cycles became regular within 20 months after withdrawal of LHRH-A in 14 of 15 girls with CPP treated with a single daily subcutaneous injection of D-Trp ${ }^{6}$, Pro ${ }^{9}-\mathrm{NET}$-LHRH for a mean period of 3.3 years.

However, there are few data available concerning resumption of gonadal function in 
patinets with CPP after discontinuation of long-term treatment with a single or twice daily subcutaneous injection of D-Ser ${ }^{6}-\mathrm{LHRH}$. Also, there are few reports of any difference in suppression of hypothalamo-pituitarygonadal function in patients with CPP between the treatment with a single and twice daily subcutaneous injection.

Swaenepoel C et al..$^{9)}$ reported that menstruation occurred with a delay varying from 2 to 28 months after therapy in 14 of 15 girls with CPP treated with monthly muscular injections of Decapeptyl at a dose of $60 \mu \mathrm{g} / \mathrm{kg}$ for a mean period of 2.5 years. Oostdijk W et $a l .{ }^{10)}$ reported that among 20 girls with CPP treated with monthly muscular injections of D-Trp ${ }^{6}$-LHRH for 4 years, 11 girls had menses 3.1-10.6 months after therapy and the other 9 had no menarche 12-16 months after therapy. The reasons for the delay of menarche in female patients with CPP treated with LHRH$A$ in these reports remain to be resolved.

To our knowledge, there have been no reports of the monthly changes of serum or urinary gonadotropins and ovarian hormones in patients with CPP during and after withdrawal of treatment with LHRH-A. We studied hypothalamo-pituitary-gonadal function during and after treatment with LHRH-A, using consecutive 30-day FMV urine specimens from patients with CPP. During treatment with LHRH-A, urinary LH excretion was suppressed more remarkably than urinary FSH excretion in all patients. Urinary FSH during treatment with twice daily injections of D-Ser ${ }^{6}$-LHRH in patients 2 and 3 was more clearly suppressed than that of FSH treated with a single daily injection in patient 1 . The urinary excretion patterns of these hormones did not return quickly to a pubertal pattern after withdrawal of treatment in these female patients. Low urinary LH and FSH excretions during treatment with LHRH-A returned at first to early pubertal and then to midpubertal patterns. Among our 5 female patients with CPP, gonadotropin and ovarian hormone excretion and the clinical progress through puberty were resumed rapidly after withdrawal of long-term LHRH-A treatment only in one patient with a hypothalamic hamartoma (patient 5). Among the remaining 4 female patients with idiopathic CPP, patient 1, treated with a single injection and intranasal spray of D-Ser ${ }^{6}$-LHRH, had regular menses after withdrawal of treatment. In this patient, urinary FSH excretion during treatment was inconpletely suppressed compared with that of 2 other patients treated with twice daily injections. This seemd to be a favorable sign for the resumption of gonadal function after withdrawal of LHRH-A. In the other 3 patients with idiopathic CPP, menses occurred late after withdrawal of LHRH-A and were disturbed. Four females (patients 1-4) were middle school students when the treatment was stopped. Patient 2 suffered psychological stress in middle school and had irregular menses. Patient 4 had menarche and thereafter amenorrhea without any known reason in middle school. Patient 3 practised hard exercise in middle school after withdrawal of LHRH-A and has had no menarche yet. More than 1.5 years after withdrawal of LHRH-A, 2 female patients (patients 1,3) showed pubertal serum LH and FSH responses to LHRH (Fig. 1). The Pituitary had responded in these 2 patients at this point. Just before LHRH loading, urinary hormonal excretion patterns in these 2 patients were different. Urinary hormonal patterns in patient 1 were similar to the normal female mid-pubertal patterns, as previously reported. ${ }^{14)}$ Patient 1 resurred werses just after the LHRH loading. However, urinary gonadotropin and ovarian steroid excretion was low in patient 3 , and menses did not occur.

Central causes of suppression of $\mathrm{LHRH}$ release include chronic systemic diseases, endocrinopathies such as diabetes mellitus, stress, intense athletic exercise and malnutrition. The mechanisms whereby LHRH secretion is inhibited by the central causes of gonadal dysfunction have not yet been fully elucidated. Investigations of gonadotropin secretion in patients with hypothalamic oligomenorrhea or amenorrhea have shown a 
range of patterns of gonadotropin pulses from total absence to abnormalities in frequency and amplitude ${ }^{18)}$.

Urinary hormonal patterns in patients 2 and 3 seemed to suggest a continued suppression of LHRH release. This may be partly related to the long-term use of LHRH-A, but seems to be partly caused by stress. These urinary hormonal patterns in patient 4 were thought to show the interuption of pubertal progress after withdrawal of LHRH-A. The reason for the delay of transition to regular menses is unclear.

In our 3 male patients with CPP treated with LHRH-A, the levels of serum testosterone and gonadotropins after withdrawal of LHRH-A increased rapidly and reached adult levels earlier than those of female patients.

The urinary gonadotropin and ovarian hormone excretion patterns were thought to be useful for evaluation of the reactivation of the hypothalamo-pituitary-gonadal axis in patients with CPP treated with LHRH-A. These results need comfirmation in a larger series. These patients treated with long-term LHRH-A will need follow-up and evaluation of reproductive function.

\section{References}

1. Lee PA: Medroxyprogesterone therapy for sexual precocity in girls. Am J Dis Child 1981, 135: 443-45.

2. Stanhope R, Huen KF, Buzi F, Preece MA, Grant DB: The effects of CA on the growth of children with central precocious puberty. Eur J Pediatr 1987, 146: 500-3.

3. Stivel MS, Kauli R, Kaufman H, Laron Z: Adrenocortical function in children with precocious sexual development during treatment with CA. Clin Endocrinol 1982, 16: 163-9.

4. Manasco PK, Pescovitz $\mathrm{OH}$, Feuillan PP, Hench KD, Barnes KM, Jones $\mathrm{J}$ et al: Resumption of puberty after long term luteinizing hormone-releasing hormone agonist treatment of central precocious puberty. J Clin Endocrinol Metab 1988, 67: 368-72.

5. Suzuki A, Suwa S, Katsumata N, Maesaka $\mathrm{H}$ : Treatment of true precocious puberty by LHRH analog. Hormone and Rinsho 1986, 34: 589-96.

6. Roger M, Chaussain JJ, Berlier P, Bost M, Canlorbe $\mathrm{P}$, Colle $\mathrm{M}$ et al: Long term treatment of male and female precocious puberty by periodic administration of a long-acting preparation of D-Trpluteineizing hormone-releasing hormone microcapsules. J Clin Endocrinol Metab 1986, 62: 670-7.

7. Tanaka T, Hibi I, Kato K, Saito S, Shimizu N, Suwa S, et al: A dose finding study of a super long-acting luteinizing hormonereleasing hormone analog (Leup rolide acetate Depot, TAP-144-SR) in the treatment of central precocious puberty. Endocrinol Japan 1991, 38: 369-76.

8. Styne DM, Harris DA, Egli CA, Conte FA, Kaplan SL, Rivier J et al: Treatment of true precocious puberty with a potent luteinizing hormone-releasing factor agonist; Effect on growth, sexual maturation, pelvic sonography and the hypothalamic-pituitary-gonadal-axis. J Clin Endocinol Metab 1985, 61: 142-52.

9. Swaenepoel C, Chaussain JL, Roger M: Long-term results of long-acting LHRH agonist in central precocious puberty. Horm Res 1991, 36: 126-30.

10. Oostdijik W, Gevers EF, Drop SLS, Rikken $\mathrm{B}$, Hummenlink $\mathrm{R}$, Partsch $\mathrm{CJ}$ et al: Growth and pubertal development during and after treatment with a slow-release gonadotropin-releasing hormone agonist in central precocious puberty. Horm Res 1991, 36: 121-5.

11. Kauli R, Kornreich L, Laron Z: Pubertal development, growth and final height in girls with sexual precocity after therapy with the GnRH analog D-TRP-6-LHRH. Horm Res 1990, 33: 11-7.

12. Maesaka H, Suwa S, Tachibana K, Kikuchi N.: Quantitation of urinary gonadotropins in normal children. pediatr 
Res 1990,28: 401-4.

13. Page LA, Beauregard LJ, Bode $\mathrm{HH}$, Beitins: Hypothalamic-pituitary-ovarian function in menstruating women with Turner syndrome $(45, \mathrm{X})$ Pediatr Res 1990 , 28: 514-7.

14. Maesaka H, Suwa S, Tachibana K, Kikuchi N, Adachi M: Monthly urinary LH. FSH and sex steroid secretory patterns in normal pubertal girls, Turner syndrome and pubertal treated patients with primary hypothyroidism. Hormone and Rinsho 1991, 101: 1023-9.

15. Takami T, Tezuka T, Manita H, Kanbegawa A: A simple method for radioimmunoassay of total estrogen in urine. Foria
Endocrinil Jpn. 1983, 59: 10-9.

16. Manita H, Kanbegawa A: Studies on the measurements of urinary pregnanediol by radioimmunoassay. Folia Endocrinol Jap 1978, 54: 11-22.

17. Linde RB, Doelle GC, Alexancer N, Kirchner F, Vale W, Rivier J et al: Reversible inhibition of testicular steroidgenesis and spermatogenesis by a potent gonadotropinreleasing hormone agonist in normal men. New Eng J Med 1981, 305-663.

18. Mansfield MJ and Emans SJ: Anorexia nervosa, athletics and amenorrhea, Adolescent gynecology, Pediatr Clin N Amer 1989 36: 533-49. 